\title{
European Analytical Column No. 43
}

\section{EuCheMs 6

\author{
Ivo Leito • Wolfgang Buchberger • Paul J. Worsfold
}

Published online: 5 March 2015

(C) Springer-Verlag Berlin Heidelberg 2015

\section{Information from the European Association for Chemical and Molecular Sciences Division of Analytical Chemistry}

The 45th Annual Meeting of the Division of Analytical Chemistry (DAC) was successfully held on 31 August 2014 in Istanbul prior to the opening of the fifth European Association for Chemical and Molecular Sciences Chemistry Congress. Paul Worsfold as current Chair of DAC welcomed delegates and observers from 15 countries attending the meeting. The updated DAC strategy for 2015-2017 was approved at the meeting, and can be found at http://www.euchems.eu/ divisions/analytical-chemistry.html.

In 2015, the prime event within the activities of DAC will be EUROANALYSIS XVIII, which will be held in Bordeaux, France, at the Convention Centre (Bordeaux-Lac), 6-10 September 2015, under the auspices of the Societé Chimique de France. EUROANALYSIS started in 1972 and is a broadspectrum conference on analytical chemistry organized on a regular basis, with its venue rotating between European countries. EUROANALYSIS has established itself as the premier European meeting for discussion and presentation of

\section{Leito}

Institute of Chemistry, University of Tartu, Ravila 14a,

50411 Tartu, Estonia

e-mail: ivo.leito@ut.ee

W. Buchberger $(\bowtie)$

Analytische Chemie, Universität Linz, Altenbergerstrasse 69,

4040 Linz, Austria

e-mail: wolfgang.buchberger@jku.at

P. J. Worsfold

School of Geography, Earth and Environmental Sciences, Plymouth

University, Plymouth PL4 8AA, UK

e-mail: pworsfold@plymouth.ac.uk analytical chemistry in a global sense, and constitutes a forum for analytical chemists from academia, governance and industry, allowing the formation of networks between chemical societies and their members working in the diverse fields of analytical sciences. This scientific event is returning to France after nearly 40 years, and will be a unique chance to obtain comprehensive insights into contemporary analytical chemistry. Among the highlights of EUROANALYSIS XVIII will be the Robert Kellner Lecture given by Bernhard Lendl from Vienna, Austria, and the presentation of the newly established DAC-EuCheMS Award to Miguel Valcárcel from Córdoba, Spain. Both the Robert Kellner Lecture and the DACEuCheMS Award are sponsored by Springer.

EUROANALYSIS XIX will take place in Stockholm, Sweden, and will be organized by the Swedish Chemical Society. The tentative dates are 27-31 August 2017.

The next Annual Meeting of DAC will be held in Bordeaux on 6 September 2015, and a decision about a new Chair of DAC for 2017-2019 will be made. The Steering Committee of DAC has nominated Slavica Ražić to succeed Paul Worsfold. Other nominations are welcome, and an official letter from a member society of DAC should be sent to the Chair or the Secretary.

Currently, DAC operates six study groups devoted to major topics of particular importance, namely "Education in Analytical Chemistry", "Bioanalytics", "History”, "Quality Assurance and Accreditation", "Chemometrics" and "Archeometry and Cultural Heritage in Analytical Chemistry" (see http:// www.euchems.eu/divisions/analytical-chemistry/newscurrent-activities-conferences-and-events/study-groups-andtask-forces.html). These study groups are evaluated after 3 years and may be renewed.

In this European analytical column, Ivo Leito provides a personal view on metrology in chemical analysis. 


\section{Metrology in chemical analysis}

Metrology lies at the foundation of any measurement. Metrology in physics has been a mature science for a long time, and metrology of chemical measurements (metrology in chemistry, $\mathrm{MiC}$ ) as a discipline is also approaching maturity. The main concepts have now been firmly established [1], and the tools-certified reference materials (CRMs) and interlaboratory comparisons (ILCs) - are available in increasing diversity. There are guidance materials (extensive sets of guidance materials on $\mathrm{MiC}$ are available from Eurachem at http://www.eurachem.org/ and from Nordtest at http://www. nordtest.info/), textbooks [2-4], training courses [5, 6] and even university study programmes [7-9] addressing MiC or some of its subtopics. Also, when it comes to practical application by laboratories involved in routine analysis, the situation has improved a great deal during the last decade. Nevertheless, challenges still remain as evidenced by, for example, discrepancies between the results of participants in ILCs [10-12]. The aim of this contribution is to review briefly why this is so and give some guidance on the most important $\mathrm{MiC}$ activities for any laboratory.

The difficulties in applying metrological concepts in chemistry originate largely from the following:

1. In chemical analysis the analyte is typically determined in the presence of (often numerous) other substances in the sample, many of them at higher (often by orders of magnitude) concentrations than the analyte. Many of them can, in principle, contribute to the analytical signal, leading to higher results (sometimes they can lead to lower results, e.g. matrix effects in liquid chromatographyelectrospray ionization mass spectrometry [13]). Thus, there is the problem of limited selectivity: the question therefore is often not "How accurately can one measure the analytical signal?" but rather "How can one ensure that the signal is wholly due to the analyte and does not include a contribution from some interferent(s)?" [14].

2. To achieve sufficient selectivity, most analytical methods involve one or more separation steps (e.g. extraction, precipitation, chromatography). Although these steps are quite successful in removing interferents, they often (mostly) also remove some of the analyte, leading to lower results.

As can be seen, the main problems (i.e. the main uncertainty contributions) in a chemical measurement usually come not from the measurement technique itself but rather from the object under investigation (see, e.g., [15] for examples in spectrophotometry).

In this complex situation, what should a routine laboratory do? The author has attempted to formulate some simple and pragmatic advice below. It is largely based on the author's experience of collaboration with such laboratories. What is described below is by no means "the full story", but is rather a starting point. It assumes that the methods used in a laboratory are, with reasonable probability, fit for purpose (which is usually the case).

Compare your values with reference values Comparing your results for a sample with an independent reference value for the same (or identical) sample is useful for confirming that your results have acceptable trueness and that the measurement uncertainty estimate is adequate (or at least suitable for obtaining data for measurement uncertainty evaluation). However, such a comparison has an additional benefit: good agreement between your result and the reference value also indicates that the selectivity of your analytical method (procedure) is probably adequate and that the robustness is good. The result of such a comparison can, depending on its intended further use, be expressed in different ways, e.g. as a zeta or $E_{\mathrm{n}}$ score [16] or as a bias [17].

There are several ways of "realizing" a reference value, all of which have different levels of reliability. The guidance below should therefore be considered in the broadest possible sense.

Perhaps the most obvious approach is analysing CRMs using the analytical method established in your laboratory. The reference values carried by CRMs are highly reliable. To be useful, the certified analyte or analytes of the CRM have to be the same as those required in the target sample(s) and the matrix, and concentration range or ranges of the analyte(s) in the CRM have to be similar to what is commonly encountered in your laboratory. The main obstacle that frequently emerges is that there is no CRM available for the required analytematrix-concentration combination. CRMs may be unavailable because the analyte-matrix combination is not common or because the analyte (e.g. dissolved oxygen, peroxides) and/ or the matrix is unstable.

In the case of many analyte-matrix combinations, satisfactory reference values can be achieved by spiking or preparing in-house reference materials (laboratory reference materials). The main prerequisite is that the matrix has to allow homogenization of the spiked analyte content.

CRMs may be unavailable for a particular analyte-matrixconcentration combination, and the preparation of laboratory reference materials can be difficult (e.g. if the matrix is solid and highly inhomogeneous). In such cases, nevertheless, ILCs may be available. In contrast to CRMs, ILC samples need not be stable for extended periods, which means that ILCs can also be undertaken with less stable analytes. Most of the ILCs in which commercial laboratories participate are the so-called proficiency tests, and instead of metrological reference values, they use consensus values based on the participants' results, which are generally of lower reliability. However, comparison 
with proficiency test consensus values is still much better than no comparison at all. Participation in ILCs is, of course, highly recommended (in fact mandatory), even if suitable CRMs exist. When no suitable ILC is available, one can be organized by the participating laboratories themselves. Although it cannot be considered a rigorous ILC, even as few as two or three laboratories analysing a few split samples and comparing results is much better than no comparison at all.

Obviously, to compare two analytical results obtained for the same sample (or identical samples), the results must refer to the same measurand.

Collect data over long periods Repeated measurements are essential when precision or trueness (e.g. using a CRM as described above) is evaluated. Replicate measurements performed within a single day allow the repeatability, $s_{\mathrm{r}}$, to be obtained, whereas replicate measurements over a longer period can be used to determine intermediate precision, $s_{\mathrm{RW}}$ (also known as within-laboratory reproducibility [17]). Although both of these characteristics have their uses, intermediate precision is certainly more useful, as it takes into account a (much) larger number of effects influencing the measurement result (uncertainty sources) for one particular parameter. This is because many effects that are systematic within 1 day (and are thus not accounted for by $s_{\mathrm{r}}$ ) become random over a longer period and are accounted for by $s_{\mathrm{RW}}[18]$. This also means that if it is correctly determined, $s_{\mathrm{RW}}>s_{\mathrm{r}}$. The longer the period, the greater the number of effects that are included in $s_{\mathrm{RW}}$, and consequently the more adequate and useful this characteristic becomes.

When $s_{\mathrm{RW}}$ is evaluated, then it is often asked, "How many data points do we need for a reliable $s_{\mathrm{RW}}$ estimate?". In fact an even more important question is "How much time should be used?". The answer is the more the better: $s_{\mathrm{RW}}$ found from eight values collected over 8 months (one per month) more adequately characterizes the method than $s_{\mathrm{RW}}$ from 16 values collected on 16 consecutive days. It is, of course, a necessary prerequisite that the sample that is analysed is homogeneous enough and is stable during the period used.

When trueness/bias is evaluated using a CRM, then again, rather than making four replicate measurements (the amount of CRM in a container is often low and it may be impossible to make many more replicate measurements) in 1 day, one should make the measurements over a period of several weeks (or a couple of months), and then the average value obtained should be compared with the reference value or used for bias calculation. It is, of course, again important to be sure that the CRM is stable over that period.

The intermediate precision and bias determined can be conveniently used by the practical and "safe" within-laboratory validation approach of measurement uncertainty estimation, perhaps best known by the formalization published by Nordtest [17]. The word "safe" here means that this uncertainty estimation approach tends to lead to somewhat overestimated rather than underestimated measurement uncertainties.

"Do not stop there" People from routine laboratories often ask questions similar to the following: "How long should the period be for determining intermediate precision?", "Should I determine parameter $\mathrm{X}$ with all my analyte-matrix combinations?", "How many different CRMs should I use for estimating the average bias of my method?". These questions are difficult to answer in an "absolute" way. If rigorous answers are given, then the probability is high that the laboratory will find that it should not use the method because so much more needs to be done to meet the ultimate requirements. In the opinion of the author, the best answer is this: when you implement a new method, you can start with a limited objective, but you must not stop there, and you should add new data on a regular basis. So, an $s_{\mathrm{RW}}$ value obtained from data collected over 4 weeks cannot be considered sufficient (preferably data collected over 1 year should be used [17]), and just one CRM for evaluation of bias is generally not enough. However, these data can be documented and used as a first approximation, and a first measurement uncertainty estimate can already be obtained. As time goes by, $s_{\mathrm{RW}}$ can be recalculated on the basis of longer time intervals, bias can be estimated using several reference values and the measurement uncertainty estimate can be recalculated accordingly.

In conclusion: constant improvement is the key to reliable analytical results.

\section{References}

1. Bureau International des Poids et Mesures (2008) JCGM 200:2008. International vocabulary of metrology - basic and general concepts and associated terms (VIM), 3rd edn. Available from http://www. bipm.org/en/publications/guides/vim.html

2. Wenclawiak BW, Koch M, Hadjicostas E (2004) Quality assurance in analytical chemistry. Springer, Berlin

3. Majcen N, Taylor P (eds) (2007) Practical examples on traceability, measurement uncertainty and validation in chemistry, vol 1. European Commission Joint Research Centre, Institute for Reference Material and Measurements, Geel

4. Majcen N, Gegevicius V (eds) (2012) Analytical measurement: measurement uncertainty and statistics. European Commission Joint Research Centre, Institute for Reference Material and Measurements, Geel

5. European Commission Joint Research Centre TrainMiC - training in metrology in chemistry. https://ec.europa.eu/jrc/en/trainmic. Accessed 31 Oct 2014

6. University of Tartu (2013) Estimation of measurement uncertainty in chemical analysis, online course. https://sisu.ut.ee/measurement/. Accessed 31 Oct 2014 
7. EACH - excellence in analytical chemistry. http://www. analyticalchemistry.eu/. Accessed 31 Oct 2014

8. EMQAL - Erasmus Mundus Master in Quality in Analytical Laboratories. http://www.emqal.org/. Accessed 31 Oct 2014

9. Measurement Science in Chemistry Euromaster ${ }^{\circledR}$. http://www.msceuromaster.eu/. Accessed 31 Oct 2014

10. Fiamegos Y, Cordeiro F, Robouch P, Emteborg H, Charoud-Gota J, Omberg LG, Rodushkin I, de la Calle B (2014) Food Addit Contam Part A Chem Anal Control Expo Risk Assess 31:63-72

11. Näykki T, Jalukse L, Helm I, Leito I (2013) Water 5:420-42

12. Interlaboratory comparisons organised at UT Testing Centre. http:// www.ut.ee/katsekoda/ILC/. Accessed 29 Oct 2014

13. Kruve A, Leito I (2013) Anal Methods 5:3035-44

14. Emons H (2014) Traceability in chemical analysis - are we ready to deliver? Paper presented at the Eurachem workshop on quality in analytical measurements, Lisbon, 19-21 May 2014
15. Sooväli L, Rõõm E-I, Kütt A, Kaljurand I, Leito I (2006) Accred Qual Assur 11:246-55

16. International Organization for Standardization (2005) ISO 13528 Statistical methods for use in proficiency testing by interlaboratory comparisons. International Organization for Standardization, Geneva

17. Magnusson B, Näykki T, Hovind H, Krysell M (2012) Handbook for calculation of measurement uncertainty in environmental laboratories. Nordtest technical report 537, 3.1 edn. Available from http:// www.nordtest.info/index.php/technical-reports/item/handbook-forcalculation-of-measurement-uncertainty-in-environmentallaboratories-nt-tr-537-edition-3.html. Accessed 1 Nov 2014

18. Leito I (2014) Recovery/bias evaluation. Presented at the Eurachem workshop on quality in analytical measurements, Lisbon, 19-21 May 2014. Available from http://www.ut.ee/EACH/?p=1936. Accessed 1 Nov 2014 